\title{
Economic costs of motor vehicle crashes involving teenaged drivers in Kentucky, 1994
}

\author{
Linda A Goldstein, Carl W Spurlock, Pamela S Kidd
}

\begin{abstract}
Objectives-To analyze data from motor vehicle crashes (MVCs) involving teenaged drivers in Kentucky for 1994, and derive cost estimates of these crashes.

Methods-Crash data were obtained from the Kentucky Traffic Accident Facts 1994 Report and the Kentucky Accident Reporting System. The National Highway Traffic Safety Administration's CrashCost program was used to generate cost estimates for Kentucky data.
\end{abstract}

Results-Teenaged drivers had significantly higher MVC fatal and non-fatal injury rates than did adult drivers. The death rates were 43.6 and 19.0 per 100000 for teens and adult drivers, respectively. Odds ratios (ORs) were calculated to estimate the relative risk for (1) involvement in an MVC, (2) fatal or incapacitating injury, and (3) fatal injury for teenaged compared with adult drivers. The crude ORs were statistically significant at each age.

Cost estimates were calculated on a per person/vehicle basis. A single fatal injury was $\$ 642700$. A critical injury was $\$ 563000$. In general, unit costs rose with increasing levels of injury severity. For the total number of fatal injuries, costs exceeded \$91 million. For non-fatal injuries and property damage only crashes, total costs were $\$ 318$ million. Overall, the total cost estimate for MVCs involving teenaged drivers was nearly $\$ 410$ million.

Conclusions-Strategies aimed to reduce the number of MVCs attributed to teenaged drivers should reduce both the number and costs of crash related deaths and injuries. Graduated driver licensing (GDL) systems are one plausible approach toward achieving this goal. By recently enacting a GDL system in Kentucky, it is anticipated that many lives and dollars will be saved.

(Injury Prevention 1997; 3: 200-206)

Keywords: death rates; injury severity; CrashCost; graduated driver licensing (GDL).

Kentucky Injury Prevention and Research Center and University of Kentucky College of Nursing Nursing

Correspondence and reprint requests to: Dr Linda A Goldstein, Kentucky Injury Kentucky Injury Prevention and Resea
Center, 333 Waller Center, 333 Waller Avenue, Suite 202, Lexington, KY 40504 2915 , USA. drivers (44 $v 19$ per 100000 licensed drivers) While teenaged drivers represented $5.6 \%$ of Kentucky's licensed driving population if $1994,{ }^{3}$ they were overrepresented as drivers iff MVCs: of all crash involved drivers (203 758) $\vec{\rho}$ $14 \%$ were teens (29 236); of all drivers. involved in fatal MVCs (516), 12\% (62) wero teens; of all drivers involved in non-fatal MVG (32 851), 5345 (16\%) were teens; finally, of aft drivers involved in property damage onlto (PDO) crashes (170 391), 14\% (23 829) were teens. ${ }^{4}$ Of the 142 persons killed in crashes involving a teenaged driver, $62(44 \%)$ were the driver. ${ }^{4}$ These data clearly indicate that the number of teenaged drivers involved in MVC far exceeds their overall representation in the licensed driving population.

Based on information from Kentucky Uniform Police Traffic Accident Reports, alcohol was not a major contributing factor to MVCs involving teenaged drivers. Only 17 (14\%) of the 120 fatal crashes involving a teen drive were alcohol related. By contrast, 242 (41\%) of 586 fatal crashes involving only adult driver were alcohol related. ${ }^{4}$

Major reports have been published preê viously that estimate the costs of injury in general, ${ }^{5}$ and the costs associated with $M V C_{8}$ in particular. ${ }^{6-9}$ While several studies have examined teenaged driver involvement in MVCs, to our knowledge only one study has examined the economic costs associated wit teen MVCs. ${ }^{10}$ This report examines data fror MVCs involving young drivers in Kentucky fo 1994, and presents the findings of a detaile cost analysis of these crashes.

\section{Methods}

KENTUCKY CRASH DATA

Data regarding the numbers of fatal, non-fata and PDO MVCs were compiled by the Kentucky State Police from all Kentucky Un form Police Traffic Accident Reports submitted in 1994, and subsequently published in th\& Kentucky Traffic Accident Facts 1994 Report Additional crash data were obtained from the Kentucky Accident Reporting Systerg (KARS) ${ }^{2}$ Information on the number of licensed drivers in Kentucky was obtained from the Transportation Cabinet, ${ }^{3}$ and popula tion data were obtained from the Bureau of the Census. ${ }^{11}$ Together, these data were used to calculate the costs of MVCs involving at least one teenaged driver in Kentucky during 1994 The data also were used to compare teenage and adult drivers with respect to the risk of involvement in MVCs, and potential differ? ences in MVC related costs.

The Kentucky State Police categorize MVC related injuries based on the five point KAB- 
CO scale, where $\mathrm{K}=$ 'killed'; $\mathrm{A}=$ 'incapacitating injury'; $\mathrm{B}=$ 'non-incapacitating injury'; C $=$ 'possible injury'; and $\mathrm{O}=$ 'no injury'. Definitions of these categories can be found in the National Safety Council's Manual on Classification of Motor Vehicle Traffic Accidents. ${ }^{12}$

Although law enforcement officials are not trained to make sophisticated 'medical' assessments of crash victims, at least one study has shown that police officers' judgments of injury severity are sufficiently accurate. Hansen et al examined the relationship between law enforcement officials' KABCO coding of injury severity at a crash scene and emergency department physicians' judgments using the same KABCO criteria. ${ }^{13}$ For nearly $50 \%$ of the cases, there was complete agreement between the police officers' and physicians' scores. Agreement was highest for the most severe $(\mathrm{K}+\mathrm{A})$ and least severe $(\mathrm{C})$ injury categories. There was less agreement between the officers and physicians in the ' $\mathrm{B}$ ' and ' $\mathrm{O}$ ' categories. Moreover, $88 \%$ of the cases were given a KABCO score within one category of the investigating officer's judgment. These results support the use of police officer assessments of injury severity in studies of MVCs (Hansen et $a l^{13}$ but see Miller $e t a l$ )

\section{COST ESTIMATION}

An IBM compatible software program, CrashCost $^{14}$ and accompanying documentation ${ }^{15}$ were obtained from the National Highway Traffic Safety Administration (NHTSA; Office of Plans and Policy, Washington, DC) to derive cost estimates. The source of CrashCost data and the derivation of each cost component for fatal and non-fatal injuries have been described in detail previously. ${ }^{6}$ Briefly, CrashCost uses the 'human capital' method to estimate the economic costs of MVCs. This approach includes both direct and indirect costs to individuals and to society that result from decreases in the general health status of those killed or injured in MVCs. Direct costs include emergency services, initial medical costs, rehabilitation costs, long term care and treatment, insurance administration expenses, legal costs, and employer/workplace costs. Indirect costs are productivity losses in the workplace and home due to temporary and permanent disability. The CrashCost program uses a $4 \%$ discount rate to estimate productivity losses based on the present value of future earnings. Estimates also are derived for costs other than those directly attributable to injury, such as property damage and travel delay. Importantly, CrashCost focuses on the economic impact of MVCs; thus, cost estimates do not include values for pain and suffering, nor do they measure decreases in 'quality of life' among MVC victims and their families.

While the cost components for fatal and non-fatal injuries are similar (see table 3), the methods of measurement are different. For non-fatal injuries, costs are calculated for injuries classified by the abbreviated injury scale (AIS). The AIS represents a standardized, albeit imperfect, system for categorizing injury type, and for quantifying severity based on immediate threat to life. ${ }^{16}$ Because MVC related injuries are usually multiple, cost estimates are based on the maximum injury severity (MAIS) level for an individual. This method assumes that the distribution of injury severity levels in any given state is similar to that for the nation as a whole. For jurisdictions that use the KABCO system, CrashCost translates KABCO frequencies into MAIS frequencies (for details, see Blincoe ${ }^{15}$ ).

CrashCost includes a number of mechanisms for determining incidence when specific state data may be missing, and for adjusting data for locality and time period. For example, KARS data provide information on the number of PDO crashes but not for the number of PDO vehicles. The number of PDO vehicles was estimated by multiplying the total number of police reported PDO crashes by $1.7 .{ }^{15}$ In addition, many MVCs are not reported to the police, or reports get lost in state records. Because unreported crashes constitute a large proportion of crash costs, the number of reported MVCs has been adjusted to account for the percentage of unreported crashes by applying the following national estimates: MAIS 1, 23.7\%; MAIS 2, $16.5 \%$; MAIS 3, $6.8 \%$; MAIS 4, $0.7 \%$; MAIS 5, 0; fatal, 0 ; PDO, 48\%. ${ }^{15}$ To adjust for unreported crashes, the number of police reported injuries and PDO vehicles are divided by one minus the per cent unreported. Finally, because CrashCost estimates are national averages expressed in 1992 terms, a locality adjustment was made for Kentucky (based on average per capita income), and for 1994 data (based on the Consumer Price Index (CPI) All Items index). (By using the All Items index, costs will be slight underestimates given larger increases in medical care costs relative to overall costs. However, because medical expenses comprise only $10 \%$ of overall costs, the results are not impacted significantly.)

\section{Results}

\section{FATALITY AND INJURY RATES}

When compared with older drivers, teenagers had significantly higher MVC related fatality and injury rates in Kentucky for 1994 (table 1). The death rate for $16-19$ year old drivers was 43.6 per 100000 licensed teenaged drivers, and 19.0 per 100000 for drivers 20 years of age and older. Injury rates were highest for 16 year olds, and decreased with increasing age (up to 19 years; data not shown). On average,

Table 1 Fatal and non-fatal injuries to drivers involved in MVCs in Kentucky, 1994

\begin{tabular}{lccccc}
\hline & \multicolumn{2}{c}{ Drivers aged $16-19$} & & Drivers aged 20+ \\
\cline { 2 - 3 } \cline { 5 - 6 } Injury level & Frequency & Rate $^{*}$ & & Frequency & Rate $^{*}$ \\
\hline Fatal & 62 & 43.6 & 454 & 19.0 \\
Incapacitating & 855 & 602 & 4884 & 204 \\
Non-incapaciting & 2021 & 1422 & 9214 & 385 \\
Possible & 2469 & 1737 & 13408 & 560 \\
None & 23829 & 16769 & 146562 & 6123 \\
\hline
\end{tabular}

*Per 100000 licensed drivers (Transportation Cabinet, Division of Driver Licensing). Data is from the Kentucky Accident Reporting System (KARS). 
non-fatal injury rates for 16-19 year olds were at least three times greater than those for older drivers (table 1). Odds ratios (ORs) were calculated to estimate the risk for three outcomes: (1) involvement in an MVC, (2) fatal or incapacitating injury, and (3) fatal injury for teenaged compared with adult drivers (table 2). For all three outcomes, the crude ORs were statistically significant at each age from 16 to 19 years. The overall OR for involvement in an MVC was greater for teenaged drivers (aged 16-19) $(\mathrm{OR}=3.29$, confidence interval $(\mathrm{CI})$ $=3.26$ to 3.34 ), and the risk of involvement in a fatal or incapacitating injury MVC was nearly as high $(\mathrm{OR}=2.91, \mathrm{CI}=2.72$ to 3.11$)$. The risk of a teen driver sustaining a fatal injury was more than twice that for adult drivers (OR = $2.30, \mathrm{CI}=1.77$ to 2.99$)($ table 2$)$.

\section{UNIT COSTS}

To estimate the costs of MVCs involving at least one teenaged driver, we derived an overall estimate of the costs of MVCs in Kentucky for 1994. These costs were calculated for injury and non-injury related expenses on a 'unit' (that is, per injured person or per damaged vehicle) basis, and are presented in table 3. CrashCost estimated the cost of a single MVC related fatality at $\$ 642683$. The most costly fatal injury expense category was productivity (wage work and household work), accounting for $80 \%$ of the total costs. Market productivity is the present discounted (4\%) value of lost wages and fringe benefits over the victim's remaining life span. Household productivity is the present value of activities performed in the home, valued at the market price to hire

Table 2 Comparison of teenaged drivers with all other licensed drivers in three types of MVCs in Kentucky, 1994

\begin{tabular}{|c|c|c|c|c|c|c|}
\hline \multirow[b]{2}{*}{ Age } & \multicolumn{2}{|c|}{ Involvement in $M V C$} & \multicolumn{2}{|c|}{$K+A$ injuries } & \multicolumn{2}{|c|}{ Fatal injuries } \\
\hline & Crude $O R^{*}$ & $95 \% C I$ & Crude OR & $95 \% C I$ & Crude $O R$ & $95 \% C I$ \\
\hline $\begin{array}{l}16 \\
17 \\
18 \\
19 \\
16-19\end{array}$ & $\begin{array}{l}5.16 \\
3.63 \\
2.90 \\
2.61 \\
3.29\end{array}$ & $\begin{array}{l}5.01 \text { to } 5.32 \\
3.54 \text { to } 3.73 \\
2.83 \text { to } 2.98 \\
2.54 \text { to } 2.67 \\
3.26 \text { to } 3.34\end{array}$ & $\begin{array}{l}4.40 \\
2.78 \\
2.73 \\
2.43 \\
2.91\end{array}$ & $\begin{array}{l}3.82 \text { to } 5.07 \\
2.40 \text { to } 3.19 \\
2.40 \text { to } 3.10 \\
2.13 \text { to } 2.78 \\
2.72 \text { to } 3.11\end{array}$ & $\begin{array}{l}2.44 \\
2.56 \\
1.87 \\
2.45 \\
2.30\end{array}$ & $\begin{array}{l}1.23 \text { to } 4.68 \\
1.53 \text { to } 4.24 \\
1.08 \text { to } 3.19 \\
1.52 \text { to } 3.90 \\
1.77 \text { to } 2.99\end{array}$ \\
\hline
\end{tabular}

$\mathrm{OR}=$ odds ratio; $\mathrm{CI}=$ confidence interval; $\mathrm{K}$ (killed) $+\mathrm{A}$ (incapacitating injury).

${ }^{\star}$ Referent group was drivers $\geqslant 20$. someone else to accomplish these tasks. ${ }^{9}$ Insurance administration and legal/court costs accounted for $17 \%$ of the costs per fatality. The estimated cost of a single critical injury (MAIs. 5) was $\$ 562905$. For critical injuries, medical expenses accounted for $45 \%$, and productivity. losses accounted for $33 \%$ of the total unit costs. Other expenses ranged from $\$ 5700^{\circ}$ (MAIS 1) to $\$ 151000$ (MAIS 4). In generale estimated unit costs rose with increasing levelo of injury severity. These unit cost estimates ar $\bar{\phi}$ not age specific (see below); they have been adjusted only for locality (that is, Kentucky 2 and for the year of interest (that is, 1994).

TOTAL COSTS

To calculate the overall costs of MVCs invol ving teenaged drivers, unit costs were multiiv plied by the number of fatal, non-fatal, anळ PDO MVCs in which at least one teenaged driver was involved. For example, a single fatat injury estimated to cost $\$ 642683$, was multi $\$$ plied by 142 (the number of persons killed in crash involving a teenaged driver) to obtain $\$$ total cost estimate of $\$ 91.2$ million for all fata injuries (table 4). Following this procedure for all injury levels and for PDO vehicles resulted ino a total cost estimate of $\$ 410$ million. Because drivers 'at fault' cannot be conclusively identie fied from crash reports, this total includes estimates for multivehicle crashes where an other (that is, adult) driver may have been a fault. Thus, total costs may be an overestimation of the teen driving problem in economic termso

Table 4 Total costs (\$) of MVCs involving a teenaget driver in Kentucky, 1994

\begin{tabular}{|c|c|c|c|}
\hline Category & Unit cost & Frequency* & Total cost \\
\hline \multicolumn{4}{|l|}{ Injury level } \\
\hline MAIS 1 & $5724 \times$ & $18834=$ & 107805816 \\
\hline MAIS 2 & $25076 \times$ & $2171=$ & 54439996 \\
\hline MAIS 3 & $78861 \times$ & $698=$ & 55044978 \\
\hline MAIS 4 & $150599 \times$ & $85=$ & 12800915 \\
\hline MAIS 5 & $562905 \times$ & $45=$ & 25330725 \\
\hline Fatal & $642683 \times$ & $142=$ & 91260986 \\
\hline PDO vehicle & $1369 \times$ & $46031=$ & 63016439 \\
\hline Total & & & 409699855 \\
\hline
\end{tabular}

^Frequency=the sum of police reported crashes and an estimate for unreported crashes. CrashCost models injuries by translating KABCO frequencies into MAIS frequencies.

Table 3 Unit cost estimates (\$) of MVCs by expense type and injury severity in Kentucky, 1994

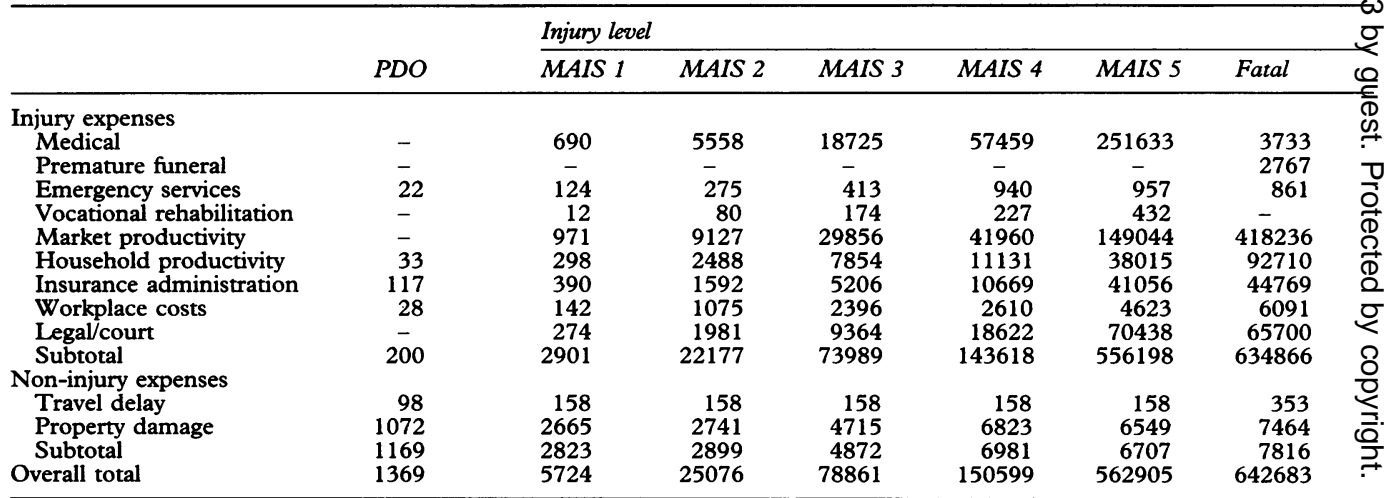

Unit costs are on a per person/per vehicle basis. Numbers may not add to totals due to rounding. Estimates were derived by using NHTSA's CrashCost software and were adjusted for locality (Kentucky) and current year (1994). 


\section{AGE SPECIFIC COSTS}

In addition to determining the economic costs for all persons involved in MVCs where at least one teenager was a driver, we calculated estimates for the teenaged drivers themselves. It is not possible to calculate cost estimates for specific age groups with the CrashCost program; however, appropriate data for this analysis were provided by Dr Ted Miller and his associates at the Children's Safety Network (CSN). ${ }^{17}$ These Kentucky specific data included the estimated cost per highway injury by age group and injury severity (KABCO) for the same cost categories included in the CrashCost program. By using these cost estimates (table 5) and the KABCO distribution of MVC related injuries to $16-19$ year old drivers (table 6), ${ }^{2}$ we derived the total estimated MVC related costs for involved teenaged drivers in Kentucky for 1994 (table 7). For the 62 teen drivers fatally injured in MVCs, cost estimates were more than $\$ 53$ million. Across all categories, total estimates were close to $\$ 136$ million. The average cost per injury category was $\$ 4755$. For comparison, the CSN cost estimates (table 5) for all ages were multiplied by the KABCO distribution of injuries for the

Table 5 Total estimated costs (\$) of MVC related injuries by age and injury severity

\begin{tabular}{llllll}
\hline & \multicolumn{3}{l}{ Injury severity } & & \\
\cline { 2 - 6 } & $O$ & $C$ & $B$ & $A$ & $K$ \\
\hline 15-19 years & 501 & 5298 & 10303 & 43106 & 857159 \\
All ages & 635 & 6219 & 11435 & 42835 & 746264 \\
\hline
\end{tabular}

In 1994 dollars and adjusted to Kentucky prices. Used for motor vehicle occupant, pedestrian, and bicycle injuries. Modified from Miller. ${ }^{17}$

Table 6 Frequency of MVCs by age of driver and injury severity

\begin{tabular}{lrrrrr}
\hline & \multicolumn{7}{l}{ Injury severity } \\
\cline { 2 - 6 } & $O$ & $C$ & \multicolumn{1}{c}{$B$} & \multicolumn{1}{c}{$A$} & \multicolumn{1}{c}{$K$} \\
\hline 16-19 years & 23829 & 2469 & 2021 & 855 & 62 \\
20+ years & 146562 & 13408 & 9214 & 4884 & 454 \\
All ages & 170391 & 15877 & 11235 & 5739 & 516 \\
\hline
\end{tabular}

Data is from the 1994 Kentucky Accident Reporting System (KARS).

Table 7 Total cost estimates (\$) for teenaged (16-19) drivers involved in MVCs

\begin{tabular}{lrrr}
\hline Injury severity & Frequency & Costinjury & \multicolumn{1}{c}{ Total cost } \\
\hline K & $62 \times$ & $857159=$ & 53143858 \\
$\mathrm{~A}$ & $855 \times$ & $43106=$ & 36855630 \\
$\mathrm{~B}$ & $2021 \times$ & $10303=$ & 20822363 \\
$\mathrm{C}$ & $2469 \times$ & $5298=$ & 13080762 \\
O & $23829 \times$ & $501=$ & 11938329 \\
Total & 29236 & & 135850942 \\
\hline
\end{tabular}

Table 8 Total cost estimates (\$) for adult (20+) drivers involved in MVCs

\begin{tabular}{lrrr}
\hline Injury severity & Frequency & Costinjury & \multicolumn{1}{l}{ Total cost } \\
\hline K & $454 \times$ & $746264=$ & 338803856 \\
A & $4884 \times$ & $42835=$ & 209206140 \\
B & $9214 \times$ & $11435=$ & 105362090 \\
C & $13408 \times$ & $6219=$ & 83384352 \\
O & $146562 \times$ & $635=$ & 93066870 \\
Total & 174522 & & 829823308 \\
\hline
\end{tabular}

$20+$ drivers (table 6) to derive the total MVC related costs for all adult drivers in Kentucky for 1994 (table 8). Clearly, higher frequencies result in higher total cost estimates. However, for all adult drivers the average cost per injury category was $\$ 4647$, slightly lower than that calculated for teens alone.

\section{Discussion}

In the US, MVCs are the leading cause of death and disability for teenagers of driving age.$^{18}$ Moreover, teenaged drivers account for a disproportionate number of MVCs when compared with older drivers. ${ }^{18}$ Generally, higher rates of MVC involvement are attributed to driving inexperience, poor decision making skills, and a propensity for risk taking behavior. ${ }^{19}$ Kentucky teens are no exception. In 1993 and 1994, Kentucky ranked first and ninth, respectively, in teen death rates from MVCs. ${ }^{1}$ In the current study, NHTSA's CrashCost program was used to derive cost estimates for MVCs involving teenaged drivers in Kentucky for 1994. Our findings show the economic toll of these crashes and further highlight the importance of taking steps to reduce the number and subsequent costs of these crashes.

Among teenaged drivers involved in MVCs in 1994, the death and injury rates were close to three times higher than were those among older drivers (table 1). Rates were highest among 16 year olds, and decreased with age up to 19 years (data not shown). Similarly, 16 year olds were at greater risk for involvement in MVCs, for sustaining fatal or incapacitating injuries, or being fatally injured in an MVC (table 2). ORs indicated that for each MVC outcome, risk decreased with increasing age. These data are consistent with the notion that 16 year olds represent the key at-risk population. Nationally, $35 \%$ of all 16 year old drivers were involved in an MVC in 1994. The percentages decreased to $31 \%$ among 17 year olds, $27 \%$ for 18 year olds, and $24 \%$ for 19 year olds. Among 20-24 year olds, the percentage was even lower at $18 \% .^{20}$

That alcohol was not a major contributing factor in teenage MVCs in Kentucky may be surprising; however, national data showed that for 1993 , only $5 \%$ of 16 year old drivers killed in MVCs had blood alcohol concentrations above the legal limit. ${ }^{19}$ Although this number increased to $28 \%$ among $17-19$ year old drivers, among drivers 20 years of age and older, nearly half $(48 \%)$ of the fatal MVCs involved alcohol.

Previous studies that have estimated the economic costs of MVCs used MVC related injury data from sources that derive estimates of fatal and non-fatal injuries on a national level. ${ }^{69}$ In the US, the total economic cost of MVCs and MVC related injuries was estimated at $\$ 137.5$ billion in $1990,{ }^{6}$ and at $\$ 150.5$ billion in 1994..$^{9}$ The CrashCost software allows for estimating the costs of MVCs in state or local jurisdictions by providing a means to adjust for the state specific economy and for current year of interest. 
The derivation of unit costs (table 3 ) serves the primary purpose of converting the CrashCost program's national data from 1992 price levels to Kentucky's price levels for 1994. On average, unit cost estimates for Kentucky in 1994 were $17 \%$ lower than those for the US in $1990^{6}$ after conversion to 1994 dollars. (The adjustment factor used was 1.13 , which is the ratio of the $1994 \mathrm{CPI}(148.2)$ to the $1990 \mathrm{CPI}$ (130.7).)

For total cost estimates of MVCs involving teenaged drivers (table 4), the MAIS 1 injury category was estimated as the most costly, totaling nearly $\$ 108$ million and accounting for $26 \%$ of total costs. Fatal injury was the next most costly category, with estimates totaling more than $\$ 91$ million and accounting for $22 \%$ of the total. PDO vehicles had the highest incidence, but accounted for only $15 \%$ of the total estimated costs at $\$ 63$ million. By contrast, for the US in 1990, PDO crashes was the most costly category, totaling nearly $\$ 36$ billion and accounting for $26 \%$ of the total MVC costs. ${ }^{6}$ It is unlikely that this disparity is the result of differences in the crash reporting threshold, for Kentucky's threshold is not atypical (for example, $\$ 500$ damage). However, it is possible that a greater number of PDO crashes go unreported in Kentucky than do such crashes in other states. It is also possible that because Kentucky is largely a rural state, the ratio of severe injury to PDO MVCs is much larger than that for more urban areas. In general, faster traveling speeds are common on rural roads, and increased speed leads to more severe injury crashes.

While CrashCost proved adequate for estimating the economic costs of MVCs involving at least one teenaged driver, the program did not provide a means for estimating the economic costs of MVCs among different age groups. For example, do economic cost estimates differ across age groups, and what are the costs associated with fatal and non-fatal injuries to the teenagers themselves who are involved in MCVs? To answer these questions, we used age specific data for Kentucky provided to us by researchers at CSN. ${ }^{17}$

According to the CSN data (table 5), cost estimates for both the fatal $(K ; \$ 857159)$ and incapacitating injury $(\mathrm{A} ; \$ 43106)$ categories were greater for 15-19 year olds than were the estimates for all ages (\$746 264 and $\$ 42835$, respectively). By contrast, cost estimates for the non-incapacitating (B), possible $(\mathrm{C})$, and no injury $(\mathrm{O})$ categories were lower for 15-19 year olds than were the estimates for all ages (table $5^{17}$ ). Thus, age becomes an important factor when examining the costs of injury by level of severity.

Of the 142 persons killed in teen driver crashes in Kentucky during 1994, 62 (44\%) were the teenaged driver. ${ }^{4}$ By multiplying the cost estimates for $15-19$ year olds (table $5^{17}$ ) by the incidence of injuries sustained by $16-19$ year old drivers (table $6^{2}$ ), we derived a total of $\$ 136$ million for MVC related expenses to teen drivers alone. While teenagers may not provide financial support for their families, fatal or permanently disabling injuries from MVCs generate a tremendous economic loss by removing these youth from society as potential consumers and producers.

It is worth noting that the cost estimates $\overline{\overline{ }}$. derived by using CrashCost differ from those $\frac{T}{9}$ provided by CSN. For example, table 3 shows? that the unit cost for a fatal injury was $\$ 642$ 683. CSN's estimate (table 5) for a fatal injury was $\$ 746264$ (for all ages). There are at? least two possible explanations for the discre- $\frac{\bar{\sigma}}{\overline{\frac{D}{}}}$ pancy between these estimates for the fatal, as well as other, injury categories. First, different discount rates were used; CrashCost used a $4 \%$ \% rate, and CSN used a $2.5 \%$ rate. ${ }^{17}$ The use of 0 lower discount rates results in higher $\cos t_{-}^{-}$ estimates. Second, CrashCost used the seven $\omega_{\sigma}^{\omega}$ point MAIS injury classification system, $\overline{0}$ whereas CSN used the five point KABCO system. Thus, the injury severity categories of the two systems are overlapping and not directly comparable.

The cost estimates presented in this study represent the economic costs of injury andes non-injury related expenses as well as produc- -0 tivity losses resulting from MVCs. These cost estimates do not reflect the 'quality of life'ס्ष losses associated with MVCs such as pain, suffering, and loss of life. Several studies havee attempted to measure the dollar value of these intangible consequences (for example, Miller $e t$ $\left.a l^{810}\right)$. Thus, economic cost estimates of MVCs are relatively conservative estimates; 'comprehensive costs', which combines bothő economic costs and values for intangibles, can® be an order of magnitude higher.

\section{PAYMENT SOURCES}

In general, the MVC related expenses are borne by the individual through expenses not covered by, or which exceed, insurance bene-o fits, and by society through higher premiums and the reallocation of state and federa $\stackrel{ }{8}$ resources. According to NHTSA, the medical, costs associated with MVC related injuries wasio estimated at nearly $\$ 13.9$ billion in $1990,{ }^{6}$ and $\$ 17.0$ billion in $1994 .^{9}$ Of this 1994 total,, private insurance companies paid $\$ 9.3$ billion (55\%); government sources subsidized ap-윽 proximately $\$ 4.1$ billion $(24 \%)$; and 'other payers' (including 'self') were responsible for the remaining $\$ 3.6$ billion ( $21 \%$ ).

Clearly, private insurers pay the majority of the medical costs associated with MVC related injuries. Importantly, the financial burdenc imposed upon the private sector by teenaged drivers involved in MVCs is even greater According to the Highway Loss Data Institute the injury claim frequency for cars insured to teenagers was more than double that for carso insured to adults. ${ }^{21}$ For collision claims, cars, insured to teenagers had a $90 \%$ higher claim frequency. ${ }^{21}$

\section{LIMITATIONS}

The CrashCost software used to analyze the data for this report does have limitations. First; the software averages lost productivity costs across all age groups for each injury level. 
However, cost estimates have been shown to differ depending upon the age group(s) of interest. ${ }^{10}$ Second, the software uses proportions derived from national estimates for the distribution of injury severity, driver age, crash related costs, and crashes unreported to the police, then applies them to state data. The national estimates may not reflect the actual distributions of these factors in Kentucky. Finally, the impact of crashes involving teenaged drivers cannot be fully realized by analyzing economic aspects alone. Other studies using different approaches go into greater detail and have put monetary values on intangibles. Such analysis is beyond the scope of this paper (but see Miller $e a^{a l^{7810}}$ ).

\section{Implications for prevention}

Strategies aimed at reducing the number of MVCs attributed to teenaged drivers should reduce substantially both the numbers of crash related deaths and injuries and the costs of these crashes. The use of graduated driver licensing (GDL) systems is one important approach for reducing the number and subsequent costs of MVC related deaths and injuries among teenagers, their passengers, and other drivers. The intent of GDL systems is to provide young, novice drivers an opportunity to gain practical driving experience in low risk settings without raising the age for licensure. By design, GDL systems target the driving behaviors (for example, risk taking, speeding, inattention) and crash characteristics (for example, single vehicle involvement, nighttime occurrences, multiple vehicle occupants) of teenagers that increase their risk for crash involvement. GDL systems also include strategies for enforcement of rules and procedures, and impose strict sanctions for violations.

In March 1996, the Kentucky General Assembly passed the Graduated Drivers Licensing for Youth bill (HB400), one of the most comprehensive GDL programs in the country. Under this new legislation young, novice drivers (at least 16 years old) begin with a learner's permit and a number of driving restrictions, including a six month waiting period before applying for a license, a period of supervised driving, a night-time (midnight to 6am) driving restriction, and a reduced point threshold for license suspension as a result of traffic citations. To obtain a provisional, 'minor's' license, the teenaged driver (16-18 years old) must pass a driving skills test and complete a state approved graduated licensing or driver education course. Full licensure can be obtained at age 18. Zero alcohol tolerance $(0.02$ blood alcohol concentration) is required of drivers at all stages of licensure until the driver is 21 years of age.

The primary elements of GDL programs are delayed licensure, night-time driving restrictions, and extended periods of supervised driving. If these elements prove effective in reducing the number of deaths and injuries from MVCs involving teenaged drivers, the cost savings are likely to exceed operational costs of the program. Indeed, studies have demonstrated the effectiveness of these elements in reducing crashes among teenaged drivers. In Delaware and Connecticut, states which allow unrestricted licensing at age 16, crash rates among 16 year olds were significantly higher than were rates in Pennsylvania or New York, states that delay full licensure. ${ }^{22}$ Similarly, the effectiveness of night-time driving restrictions also has been shown in this ${ }^{22}$ and an earlier study. ${ }^{23}$ In upstate New York (9pm to 6am curfew) and Pennsylvania (midnight to 6am curfew), both total crashes and crash rates were significantly lower than predicted during restricted driving periods by $65 \%$ and $54 \%$, respectively. ${ }^{22}$ Preusser et al showed that curfew laws substantially reduced the number of crashes among 16 year old drivers that occurred during curfew hours. ${ }^{23}$ In the four states (Louisiana, Maryland, New York, and Pennsylvania) that had curfew laws, the reductions in crashes ranged from $25 \%$ (Louisiana) to $69 \%$ (Pennsylvania). In evaluating the effectiveness of supervised driving, Ferguson et al showed that in upstate New York, where unsupervised driving by 16 year olds is generally not allowed, their crash rate was about one third (0.36) that for adults. ${ }^{22}$ The rate was even lower in New Jersey (0.13), where 16 year olds are only allowed to drive with supervision.

Are these individual elements equally effective when combined in a comprehensive GDL program? An evaluation of California's provisional licensing system showed a statistically significant reduction in the rate of MVCs among 15-17 year olds. The estimated reduction was $5.3 \%$ of their average rate before the program was implemented. ${ }^{24}$ Maryland has also demonstrated small but significant reductions in the number of traffic related deaths and injuries to teenagers after implementation of a GDL system. ${ }^{25}$ In New Zealand, a GDL system was started in 1987. During the subsequent five year period $(1987-92)$ the number of serious MVC related injuries among $15-19$ year olds declined $7-23 \%$. $^{26}$

\section{Conclusion}

In this study, the cost estimates derived for MVCs involving teenaged drivers in Kentucky for 1994 clearly illustrate the enormous economic impact of these crashes on the state and its taxpayers. Attempts to reduce the number of Kentucky teenagers involved in MVCs would contribute substantially toward reducing the total numbers of traffic related deaths and injuries, and toward decreasing the costs of these crashes. By implementing a GDL program in Kentucky, a significant number of lives may be saved, injuries prevented, and economic costs substantially reduced.

We gratefully acknowledge Robert McCool for his technical assistance with the Kentucky Accident Reporting System (KARS) database. We also thank our anonymous reviewers manuscript. 
1 National Association of Independent Insurers. Phasing in the driving privilege. Des Plaines, IL: National Association of Independent Insurers, 1995.

2 Kentucky State Police. Kentucky accident reporting system (KARS) [electronic data tape]. MS-DOS version. Frankfort, KY: Kentucky State Police, Information Service Branch, 1994.

3 Kentucky Transportation Cabinet. Table of licensed drivers by age-1995. Frankfort, KY: Kentucky Transportation Cabinet, Division of Driver Licensing, 1995.

4 Kentucky Transportation Center. Kentucky traffic accident facts 1994 report. Lexington, KY: University of Kentucky College of Engineering, Kentucky Transportation Center, 1995.

5 Rice DP, MacKenzie EJ and Associates. Cost of injury in the United States: a report to Congress. San Francisco, CA:
Institute for Health and Aging and Baltimore, MD: Injury Institute for Health and Aging and Baltimore, MD: Injury Prevention Center, School of Hyg

6 Blincoe LJ, Faigin BM. The economic cost of motor vehicle crashes, 1990. Washington, DC: US Department of Transportation, National Highway Traffic Safety Administration, 1992. (Report No DOT-HS-807-876.)

7 Miller T, Viner J, Rossman S, et al. The costs of highway crashes. Washington, DC: Federal Highway Administration, 1991. (Report No FHWA-RD-91-055.)

8 Miller TR. Costs and functional consequences of US roadway crashes. Accid Anal Prev 1993; 25: 593-607.

9 Blincoe LJ. The economic cost of motor vehicle crashes, 1994. Washington, DC: US Department of Transportation, Washington, DC: US Department of Transportation, (Report No. DOT-HS-808-425.)

10 Miller TR, Lestina DC, Spicer RS. Highway crash cost in the United States by driver age, blood alcohol level, victim age, and restraint use. Accid Anal Prev (in press).

11 Bureau of the Census. Statistical abstract of the United States, edition 114. Washington, DC: US Department of Commerce, Bureau of the Census, 1994.

12 National Safety Council. Manual on classification of motor vehicle traffic accidents. 5th Ed. Washington, DC: National Safety Council, 1989.

13 Hansen AR, Popkin CL, Campbell BJ, Burton JH, Waller $\mathrm{PF}$. Comparison of police and physician judgments of inj. Comparison of police and physician judgments of victims. Proceedings of the 35th Association for the Advancement of Automotive Medicine Conference. Toronto, Canada ment of Automotive Medicine Conference. Toron
14 CrashCost [computer program]. MS-DOS version. Wahington, DC: US Department of Transportation, National Highway Traffic Safety Administration, 1994

15 Blincoe IJ Estimating crash costs in state or local jurisdictions. Washington, DC: US Department of Transportation, National Highway Traffic Safety Administration, 1994 . (Report No DOT-HS-808-135.)

16 Committee on Injury Scaling, American Association forD Automotive Medicine. Abbreviated injury scale, 1985 revision. Arlington Heights, IL: AAAM, 1985.

17 Miller TR. Costs per highway injury by age group and injury severity. Landover, MD: Children's Safety Network Thirdo Party Payers Injury Prevention Resource Center, NationalC Public Services Research Institute, 1993.

18 National Center for Statistics and Analysis. Traffic safetye facts 1994-young drivers. Washington, DC: US Depart- $\bar{\top}$ ment of Transportation, National Highway Traffic Safetye ment of Transportation,

19 Insurance Institute for Highway Safety. All the 16 year-olds didn't make it home. Status report. Arlington, VA:Insurance Institute for Highway Safety 1994; 29: (13):$1-11$. 20 National Safety Council. Accident facts, 1995. Washington, $\vec{\omega}$

21 Highway Loss Data Institute. Injury and collision losso experience by rated driver. Arlington, VA: Highway Lossio Data Institute, 1991. (Insurance Special Report No A 37.)

22 Ferguson SA, Leaf WA, Williams AF, Preusser DF. Differences in young driver crash involvement in states with varying licensure practices. Accid Anal Prev 1996; 28:0 $171-80$.

23 Preusser DF, Williams AF, Zador PL, Blomberg RD. The effect of curfew laws on motor vehicle crashes. Law and Policy 1984; 6: 115-28.

24 Hagge R, Marsh WC. An evaluation of the traffic safety impact of provisional licensing. Sacramento, CA: Department of Motor Vehicles, 1988. (Report No CAL-DMV-RSS-88-ठ 116.)

25 McKnight AJ, Tippetts AS, Marques PR. Provisional driver license system for follow-up evaluation of Maryland youthe license control demonstration project. Washington, DC. USC Dense control dertmenstration project. Washington, DC: US Traffic 669.) Administration, 1990. (Report No DOT-HS-807-

Langley JD, Wagenaar AC, Begg DJ. An evaluation of New Zealand's graduated driver licensing system. Accid Ana局 Prev 1996; 28: $139-46$.

\section{Does your child know how to use the emergency services?}

A report in Newcastle's Evening Chronicle tells how a 5 year old saved his parents and 2 week old brother in a fire. The toddler woke at 5 am to find his home filled with smoke and dialled the emergency number, 999 , himself before leading his family to safety.

\section{Fatal 'surfing' on a fire engine}

Andrew Chapman, writing in the Daily Mail (15 December 1996), tells the story of an 8 year old who was killed, trying to 'surf' on a moving fire engine in Burnley, Lancashire. He fell off the vehicle and was crushed under its wheels as it moved slowly. The death came a month after police and fire chiefs warned youngsters that the craze of jumping on appliances would end in tragedy. Several children, including some as young as 7 , had recently been found clinging to the ladders on fire engines and a girl had been thrown off as the vehicle rounded a corner at speed. The police recognised that fire engines have a fascination for children but called on parents to warn their children of the perils. 